\title{
NOTES ON \\ THE ROLE OF METAPRAGMATIC AWARENESS IN LANGUAGE USE
}

\author{
Jef Verschueren
}

\begin{abstract}
Against the background of a general theory of pragmatics, reflections are formulated on the central role of metapragmatic awareness as a specific manifestation of salience, the status of processes of meaning generation in language use in relation to the cognitive apparatus. First the notions of metalanguage and metapragmatics, as used in linguistics, are discussed. Then metalinguistic and metapragmatic phenomena are presented as reflections of metapragmatic awareness. Two ways in which indicators of metapragmatic awareness function in language use are distinguished: Their functioning as anchoring devices locating linguistic form in relation to context, and their functioning as signals of the language users' reflexive interpretations of the activities they are engaged in. Finally, some social implications of metapragmatic functioning are discussed, in particular in relation to language ideologies and identity construction.
\end{abstract}

Keywords: Pragmatics, Metapragmatics, Metapragmatic awareness, Reflexivity, Language ideology, Identity construction

\section{Introduction}

This paper argues that metalanguage is an important topic for linguistic research because it reflects metapragmatic awareness, a crucial force behind the meaning-generating capacity of language in use. The reflexive awareness in question is no less than the single most important prerequisite for communication as we know it. It is part of what Tomasello (1999) describes as people's ability to identify with others and thus to work collaboratively towards common goals. ${ }^{1}$

In a first section, the notions of metalanguage and metapragmatics will be briefly introduced and clarified. Section 2 goes into the relevance of metalinguistic or metapragmatic phenomena as reflections of metapragmatic awareness, a notion that will be situated in relation to an overall theory of pragmatics. A third section elaborates on some aspects of the functioning of metapragmatic awareness in actual language use. Finally,

${ }^{1}$ According to Tomasello, this ability to identify with others is the source of cultural learning, the cognitive switch that separates homo sapiens from primates and that explains the complex development of industries and institutions within historical (rather than evolutionary) time. 
some of the social implications of this functioning will be reviewed, in particular in relation to language ideologies and identity construction.

\section{Metalanguage and metapragmatics}

Let's start out by establishing an intertextual link - and thereby engaging in the conscious use of metalanguage. During a meeting of which this article is a side product, ${ }^{2}$ the issue was raised repeatedly of how useful the notion of METALANGUAGE was, more often than not with the implication that its usefulness was very limited. Yet, depending on the perspective one takes, the significance of the notion may range from useful and interesting to absolutely necessary. First one may regard 'metalanguage' as an identifiable object, separable from other manifestations of 'language.' Applied to the text you have just started to read, the term would cover the use of lexical items such as 'intertextual,' phrases such as "the text you have just started to read" and "thereby engaging in the conscious use of metalanguage", or utterances such as "[...] the issue was raised repeatedly of how useful the notion of 'metalanguage' was" or "what Tomasello (1999) describes as [...]." It would cover conversational interventions such as "What do you mean by that?" or "That's not what I said". Such occurrences are pervasive in most types of discourse. Hence, because of its obvious correspondence with a range of empirical facts, the notion is necessarily a useful and interesting one. Yet its usefulness, from this perspective, remains limited. One might object, for instance, that what we are concerned with is simply language about language, i.e. manifestations of language in general which happen to have language within their referential scope. We would still have to demonstrate what is so special about it - if anything. We would have to demonstrate that the reflexivity involved is neither fortuitous nor trivial.

A second way of approaching 'metalanguage' is to look at it as a dimension of language - to be found in all language use - rather than a collection of instances of metalinguistic language use. While a discussion of this dimension would have to refer to all metalinguistic phenomena covered by the object notion of 'metalanguage', it moves beyond such phenomena into the realm of basic properties of any stretch of discourse, thus significantly expanding the relevance of the notion. This approach has a reasonably long history in linguistics, where the influences of pragmatist semiotics (in particular Peirce's theory of indexicality) combined with Prague School structuralism in the person of Roman Jakobson, who may have provided the single most forceful and influential introduction of 'metalanguage' as a linguistic topic. In his "Shifters, verbal categories, and the Russian verb" (1971), Jakobson points out that the two basic ingredients of linguistic communication, the message (M) and the code (C), may both be 'utilized' (used) and 'referred to' (pointed at, mentioned). 'Referring to' is a metalinguistic activity as soon as

\footnotetext{
${ }^{2}$ Observations leading to the writing of this paper were first presented in a very different lecture on "Metapragmatic awareness and ideologies of language in socially relevant linguistic research" during the 3 rd Cardiff Round Table in Sociolinguistics, Newtown, Wales, 1-3 June 1998. The basic ideas were lifted out of that presentation and further developed in lectures given in Madrid (28 March 2000), La Corunha (29 March 2000), Poitiers (6 September 2000; École thématique "Pragmatique: Langage, Communication et Cognition") and Mar del Plata (21 September 2000; VIII Congreso de la Sociedad Argentina de Lingüística).
} 
it has ingredients of linguistic communication within its scope. This activity may take place either within or across message and code, thus yielding four types of metalinguistic usage: Messages referring to messages $(\mathrm{M} / \mathrm{M})$ are to be found in various forms of quoted and reported speech (for an authoritative treatment of which, in terms of speech about speech, Jakobson refers to Vološinov 1930); an instance of code referring to code (C/C) is the proper name, which cannot be defined without circular reference to the code itself (i.e. a name means anyone or anything to whom or to which the name is assigned); messages referring to the code (M/C) are found whenever a word is 'mentioned' rather than 'used', as in "Pup' means a young dog" or "Pup' is a monosyllable" (a topic which has been commonly debated in philosophy at least since Carnap 1937); finally, a case where code and message overlap or where an element of the code makes "compulsory reference to the given message" $(\mathrm{C} / \mathrm{M})$ is provided by the category of 'shifters' (a term borrowed from Jespersen 1921), i.e. indexical symbols such as personal pronouns, aspect, tense, mood and evidentials, which necessarily 'shift' in relation to changes in the context of use and hence in relation to the content of the message. In more general terms, Jakobson $(1960,1985)$ presented the 'metalingual function' as one of his six basic functions of language. ${ }^{3}$ Clearly, only Jakobson's $\mathrm{M} / \mathrm{M}$ and $\mathrm{M} / \mathrm{C}$ categories of metalinguistic functioning fit into the object notion of 'metalanguage', while $\mathrm{C} / \mathrm{C}$ and $\mathrm{C} / \mathrm{M}$ can only be conceived in terms of a metalinguistic dimension. This observation gives rise to a rough classification of metalinguistic phenomena into two categories, as visualized in Table 1, one included in the dimension view of metalanguage only (say 'implicit metalanguage'), the other included in both the dimension and the object view ('explicit metalanguage').

\begin{tabular}{|l|l|}
\hline \multicolumn{2}{|c|}{ metalanguage as a dimension of language use } \\
\hline \multicolumn{1}{|c|}{ metalanguage as an object } & [Jakobson's C/C $+\mathrm{C} / \mathrm{M}]$ \\
\cline { 1 - 1 } $\begin{array}{l}\text { [Jakobson's M/M }+\mathrm{M} / \mathrm{C}] \\
\text { explicit metalanguage }\end{array}$ & implicit metalanguage \\
\hline
\end{tabular}

Table 1. Metalinguistic phenomena

Because of its necessary relation to usage phenomena (the proper domain of linguistic pragmatics), the study of the metalinguistic dimension of language could be called METAPRAGMATICS. In fact, the term has been used in this way, e.g. by Michael Silverstein (1976, 1979, 1993). In Silverstein's view, strongly inspired by Jakobson but taking an interdisciplinary (primarily anthropological-linguistic) point of view, pragmatics encompasses "the totality of indexical relationships between occurrent signal forms and their contexts of occurrence, regardless of whether such contexts are other occurrent signal forms [...] or not specifically such [...]" (1993: 36). Whatever pragmatic functioning there may be, there is always the possibility of metapragmatic functioning, conceived in terms of reflexivity. He goes on to emphasize the importance of reflexivity more strongly still, taking away all suspicion that the phenomenon we are confronted with would be fortuitous or trivial:

\footnotetext{
${ }^{3}$ For a brief account of the interdisciplinary ancestry or links of these ideas, see Verschueren (1995b).
} 
Without a metapragmatic function simultaneously in play with whatever pragmatic function(s) there may be in discursive interaction, there is no possibility of interactional coherence, since there is no framework of structure - here, interactional text structure - in which indexical origins or centerings are relatable one to another as aggregated contributions to some segmentable, accomplishable event(s). (1993: 36-37)

And, "metapragmatic function serves to regiment indexicals into interpretable event(s) of such-and-such type that the use of language in interaction constitutes (consists of)." (1993: 37) In other words, there is a constant interaction between pragmatic and metapragmatic functioning. This observation definitely lifts metapragmatics or metalanguage (seen as a dimension rather than an object) from the merely interesting and useful to the absolutely necessary if we want to understand language use.

In order to make the vast field of inquiry opened up by this view more manageable, Silverstein identifies three dimensions of contrast along which metapragmatic phenomena can be usefully situated. First, he distinguishes metafunctions according to their object of meta-semiosis. Along this dimension, metapragmatics - bearing on a reflexive relation to the pragmatic or indexical dimension of language - is opposed to (while at the same time incorporating) metasemantics, which deals with the reflexivity related to the semiotic realm of sense, i.e. an "abstractable constancy in denotational capacity of grammatically constructed expressions" (1993: 41). A second dimension is formed by degrees and kinds of denotational explicitness. Most natural languages have (partially) explicit metapragmatic forms of expression, e.g. in the form of metapragmatic lexical items (such as performative verbs). There are also inherently (hence relatively explicitly) metapragmatic semanticoreferential forms such as deictic expressions. At the implicit end of the scale we find metapragmatic indexicality, i.e. indexical signaling of something about indexical signaling. It is here that one may, e.g., situate the theoretical contribution of Gumperz's (1982) 'contextualization cues', the linguistic means (often prosodic) that speakers use (usually with a very low degree of awareness) to signal how (forms occurring in) utterances are to be appropriately interpreted. Third, types of metapragmatic functioning differ in terms of the mutual calibration of the metapragmatic signaling event and the signaled pragmatic event-structure. Put simply, there is a difference, for instance, between cases in which the relationship between the two events is a 'reporting on' rather than a 'coincidence'. It is with reference to this dimension that the double communicative layering inherent in the pragmatic-metapragmatic relationship can be fully accounted for.

It is important to keep such possible distinctions in mind, while it is not necessary to adhere strictly to the associated terminology. For one thing, this author has trouble distinguishing between metapragmatics and metasemantics; even though a theoretical distinction can be made between those aspects of the meaningfulness of signs that are constant across different specific contexts and those that are connected with ongoing usage, they are hard to identify in practice. Aspects of denotational explicitness and mutual calibration between the pragmatic and the metapragmatic, on the other hand, will help to structure the following exposition. At the same time, they should function as a frame of interpretation for what follows; for instance, when we use the contrast explicit-implicit, it should be clear that this is a scale rather than a dichotomy, though because of the difficulty in giving all phenomena a specific place on the scale, the presentation will still look dichotomous.

As already mentioned, a dimension approach to metalanguage, exemplified in the 
Silversteinian formulation, implies a necessary or crucial link between the study of metalanguage or metapragmatics and pragmatics in general. The following section will be an attempt to define that link. Before doing so, however, let me specify two ways of using the term 'metapragmatics' which I want to distance myself from in what follows. Neither of them bears on the 'reflexivity' of language itself. The first is 'metapragmatics' in the sense of critical discussions of pragmatics; this belongs to the order of endeavors which any self-respecting scientific discipline has to engage in. According to the second, "Metapragmatics studies the conditions under which pragmatic, i.e. users', rules are supposed to hold" (Mey 1993: 277) - a topic which would generally be regarded as the province of pragmatics itself. ${ }^{4}$ There is a reason why such confusion could arise, but we can only explain that later. First we have to go deeper into the fundamental relationship between pragmatics and metapragmatics. In the following section we will introduce the notion of 'metapragmatic awareness' in relation to a general theory of pragmatics, arguing for the central role it plays in any type of language use, thus strengthening the view of metalanguage as a dimension rather than an object in its own right and demonstrating the relevance - indeed, necessity - of taking metalinguistic or metapragmatic functioning into account when approaching instances of language use.

\section{Pragmatics and the central role of metapragmatic awareness}

This paper is formulated against the background of a theory of linguistic pragmatics which defines language use as the adaptable and negotiable making of linguistic choices, both in production and in interpretation, from a variable (and constantly varying) range of options in an interactive effort at generating meaning (see Verschueren 1999). ${ }^{5}$ The highly dynamic processes that are involved take place in a medium of adaptability which, rejecting any strict dichotomy between society and cognition, could be labeled 'mind in society' (following Vygotsky 1978). The mental phenomena characterizing this medium of adaptability that are most visibly at work in the meaningful functioning of language are perception and representation, planning, and memory. In addition to their being determined by the workings of such mechanisms, all meaning-generating processes occupy a specific status in relation to the medium of adaptabililty. In other words, not everything that happens in linguistic behavior occupies the same place in consciousness. Various manners of processing or degrees of salience (a term originally inspired by Errington 1988) may be involved. Just consider the opening sentences of this section:

(1) This paper is formulated against the background of a theory of linguistic pragmatics which defines language use as the adaptable and negotiable making of linguistic choices, both in production and in interpretation, from

\footnotetext{
${ }^{4}$ Both of these senses, as well as the definition used in this article, occur in a special issue of the Journal of Pragmatics (Caffi (ed.) 1984) devoted to 'Metapragmatics.' See also Caffi (1998).

5 The theory in question views pragmatics as a general functional perspective on (any aspect of) language, i.e. as an approach to language which takes into account the full complexity of its cognitive, social, and cultural (i.e. 'meaningful') functioning in the lives of human beings.
} 
a variable (and constantly varying) range of options in an interactive effort at generating meaning (see Verschueren 1999). The highly dynamic processes that are involved take place in a medium of adaptability which, rejecting any strict dichotomy between society and cognition, could be labeled 'mind in society' (following Vygotsky 1978).

Though writing is a verbal activity involving a generally high degree of consciousness in the making of linguistic choices (in comparison to more spontaneous oral interaction), much in (1) is the product of quite automatic processing. Thus for someone with a reasonable command of English the verb to be quite naturally transforms into is when a correspondence with this paper is required in the present, and into are when the subject is the plural processes. Similarly, following the basic English word order subject-verb-object is hardly a matter of conscious decision-making. Even a conventionalized violation of the 'standard' rule requiring implicit subjects of non-finite clauses to be coreferential with the explicit subject of the main clause, resulting in the dangling participle rejecting, is not really the product of intentional design. On the other hand, as in most academic writing, word choice and the development of an argumentational structure are (expected to be) highly salient activities, the product of conscious effort. What happens on the interpreter side is roughly analogous.

Being a crucial aspect of what goes on when language is used (whether in uttering or in interpreting), pragmatic analyses have to come to terms with the role of consciousness, awareness, or salience - whatever the preferred term may be - in order to understand linguistic behavior. As is graphically suggested in Figure 1, salience has within its scope all the processes operating on structural choices anchored in context that contribute to the meaningful functioning of language. In other words, language users know more or less what they are doing when using language. Self-monitoring, at whatever level of salience, is always going on.

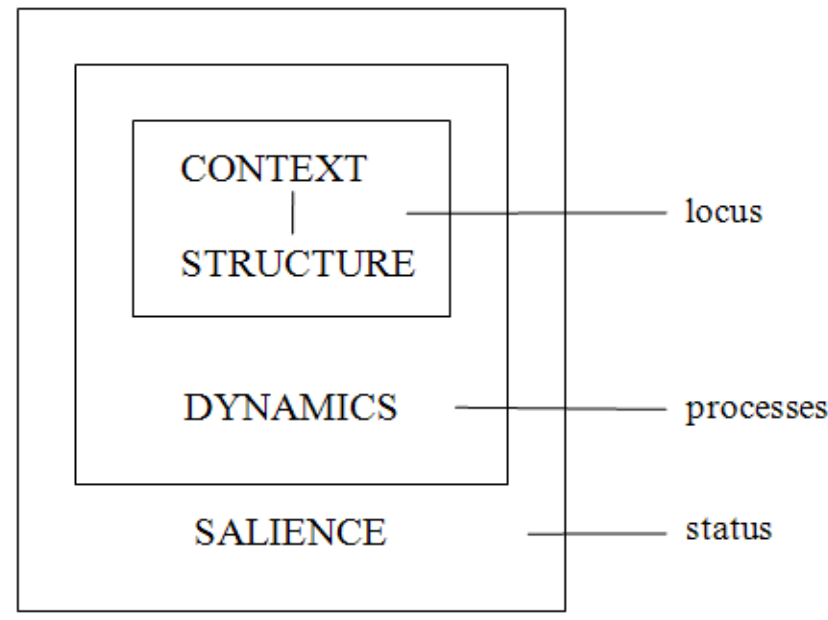

meaningful functioning

Figure 1. The structure of a pragmatic theory (Verschueren 1999, p. 67) 
It is this general aspect of language use in relation to the medium of adaptability that I call reflexive or metapragmatic awareness (a usage that is in line with the terminology anthropologists use, as reflected in Lucy (ed.) 1993). Studying this type of awareness is crucial to an understanding of verbal behavior because, like any other form of social action, language use is always interpreted, in the sense that the actors involved attach meaning to it, so that the actors' interpretations become part and parcel of what needs to be described and explained. We will return to this point in Section 3.

On the basis of these observations we may be able to understand Mey's confusion (referred to at the end of Section 1) about metapragmatics in relation to pragmatics: 'The conditions under which pragmatic rules are supposed to hold' suggests a distance between conditions and rules; the conditions, however, necessarily belong to the rules (disregarding for the moment the question whether we want to talk about rules rather than principles at all); they form a normative package as it were; but of course there is no normativity without awareness, and the norms involved are constantly negotiated and manipulated; it is at this metalevel of awareness, which is necessarily at work whenever language is used, that the proper domain of metapragmatics is situated, inseparable from but still beyond the 'rulescum-conditions' (which cannot really be broken up into 'rules' and 'conditions').

Awareness is not measurable, and the notion lends itself to easy speculation. Hence the centrality of metapragmatic awareness could easily mean the end of pragmatics as an empirical enterprise. Fortunately, the self-monitoring in question, at various levels of consciousness or salience, leaves identifiable linguistic traces. Returning to (1), just consider the following features:

- the self-referential use of this paper, which does not only refer to the overall activity of which the chosen phrase is itself a constitutive part, but which also categorizes that overall activity as a specific genre of language use, thus providing it with a specific frame of interpretation

the explicit intertextual links that are introduced by see ..., following ..., and formulated against the background of, where the first two are mainly informative while the last one also instructs the addressees how to interpret what is about to follow

- the metapragmatic description of a verbal activity carried out elsewhere, as with the linguistic action verb defines

the introduction of a modality in could be, which draws explict attention to the status of the choice in the author's conceptualization of the ideational state of affairs referred to

other metapragmatic markers such as the quotation marks in 'mind in society', which draw attention to the lexical choice-making itself, as a kind of warning against unreflective interpretation

finally, the entire stretch of discourse (and whatever follows it in this text) is about properties of language use, formulated at the metalevel of linguistic theory and analysis, and hence it is one long marker of metapragmatic awareness, abounding with categorizations, suggestions, claims, etc.

Thus, while all linguistic choice-making implies some degree of consciousness (which is not always equally observable), some choices openly reflect upon themselves or upon other 
choices. Reflexive awareness is so central that all verbal communication is self-referential to a certain degree, or that there is no language use without a constant calibration (to use Silverstein's term) between pragmatic and metapragmatic functioning. This phenomenon forms the proper domain of metapragmatics.

The range of indicators of metapragmatic awareness is not restricted to those exemplified with reference to (1) above. It includes all of Jakobson's 'shifters', Gumperz's 'contextualization cues' (such as instances of code switching), anything ever discussed under the labels 'discourse markers/ particles' or 'pragmatic markers/ particles' (such as anyway, actually, undoubtedly, I guess, you know, etc.), 'sentence adverbs' (such as frankly, regrettably), hedges (such as sort of, in a sense), instances of 'mention' vs. 'use' (again as already suggested by Jakobson), as well as direct quotations, reported speech, and more implicitly embedded "voices. " Independently of the Silversteinian tradition, though fully compatible with it, the label 'metapragmatics' has been used to describe specifically the linguistic study of one category of indicators of metapragmatic awareness, namely 'metapragmatic terms' or - more specifically still - 'linguistic action verbs' ( Verschueren 1985a, 1989b; Verschueren (ed.) 1987; Kiefer \& Verschueren (eds.) 1988). This more restricted form of metapragmatics was motivated as an empirical-conceptual approach to linguistic action, i.e. an attempt to come to grips with the varying ways in which linguistic behavior is conceptualized by those engaged in it, by way of scrutinizing empirically observable linguistic reflections of those conceptualizations (such as the verbs and verb-like expressions used, in natural language, to talk about the conceptualized behavior in question). This approach to language on language could be regarded, in a Silversteinian perspective, as a form of 'folk-metapragmatics', to be approached with due caution ${ }^{7}$. As Silverstein (1981) pointed out, speakers' awareness of pragmatic phenomena (an interesting cross-linguistic study of which is provided by Lucy (ed.) 1993) does not have to match the linguist's metapragmatic descriptions. Naïvely confusing these two may contribute to the furthering of a specific kind of folk metapragmatics inherent in Western linguistics itself. Assuming that such naïve confusion can be avoided, at least some of my further comments will be based on results obtained in this line of research.

Using the dichotomy introduced in Table 1 (which was declared to be scalar rather than dichotomous), let us assign, for the sake of easy reference in what follows, a 'place' to the different indicators of metapragmatic awareness, as reviewed briefly above, in Table 2 .

${ }^{6}$ For a more detailed overview of indicators of metapragmatic awareness, see Verschueren (1999, pp. 189-195).

${ }^{7}$ A recent plea for the study of folk linguistics (Preston 2000), linked to earlier proposals such as one by Hoenigswald (1966), is entirely in line with this interest, though formulated outside the context of a theory of pragmatics. 


\begin{tabular}{|c|c|}
\hline explicit metalanguage & implicit metalanguage \\
\hline $\begin{array}{l}\text { - metapragmatic descriptions (e.g. by } \\
\text { means of metapragmatic lexical items such } \\
\text { as speech act verbs or performative verbs) } \\
\text { - self-referential expressions } \\
\text { - discourse markers/particles or pragmatic } \\
\text { markers/particles } \\
\text { - sentence adverbs } \\
\text { - hedges } \\
\text { - explicit intertextual links } \\
\text { - quoted and reported speech } \\
\text { - 'mention' (vs. 'use') } \\
\text { - some 'shifters' (e.g. some evidentials) } \\
\text { - some 'contextualization cues' (many of } \\
\text { the above can be included in this category) }\end{array}$ & $\begin{array}{l}\text { - most 'shifters': } \\
\text { * deictic expressions (pronouns, } \\
\text { tense, etc.) } \\
\text { * aspect } \\
\text { * mood and modality } \\
\text { * (some) evidentials } \\
\text { - many 'contextualization cues' (e.g. } \\
\text { prosodic patterns, code switching, etc.) } \\
\text { - implicit 'voices' } \\
\text { [- proper names, i.e. Jakobson's C/C, } \\
\text { which may not be fully treatable on a par } \\
\text { with the other metalinguistic phenomena] }\end{array}$ \\
\hline
\end{tabular}

Table 2. Indicators of metapragmatic awareness

Returning briefly to the scalarity of the distinction, it may be useful to point at a property of (1). The fact that deictic expressions, and in particular personal pronouns, are absent from the example does not mean that there is no person deixis. Clearly, the deictic center is the author and his own work. The degree of implicitness is higher than if there would have been personal pronouns. This is a function of the genre of academic writing to which the example belongs. But genre is only one parameter that corresponds to degrees of explicitness. Developmental research (e.g. Hickmann 1993) suggests that there are also age differences in the relative use of more explcit vs. more implicit forms of metalanguage.

\section{The functioning of metapragmatic awareness}

Metapragmatic awareness (of which we should remember that it may be present at any level of salience) functions in at least two crucial ways, related to - though not coinciding with - the categories of explicit and implicit metalanguage (see Table 2.).

\subsection{Anchoring}

First of all, forms of more implicit metalanguage such as deictic expressions ${ }^{8}$ reflect an

\footnotetext{
${ }^{8}$ In his theory of 'pragmatics as implicitness' Östman (1986) excludes deixis from the realm of pragmatics (and includes it in semantics) because it represents a form of explicit rather than implicit meaning. Leaving aside the issue of the line that is drawn between semantics and pragmatics, there is no contradiction between that stance and the treatment of deictic expressions as types of implicit metalanguage: Saying that their metalinguistic functioning is more implicit (even though it leaves a 'trace') does not amount to saying that their meaning, in general, is implicit.
} 
awareness of the ways in which utterances or sets of structural choices are situated or anchored in a temporal, spatial, social or discourse context. (This metapragmatic functioning bears on degrees of salience of the line that connects STRUCTURE and CONTEXT in Figure 1.) Without such anchoring, any cognitive processing or interpretation is impossible or, as Silverstein puts it, "there is no possibility of interactional coherence" (1993: 36). This kind of function is also performed by some types of explicit metalanguage, in particular those that establish discourse deixis. In this domain, a special place is occupied by instances of self-reference, and in particular the full self-reference manifested in the performative use of speech act verbs (such as promise in I promise that I will come tomorrow), requiring the kind of calibration between the metapragmatic signaling event and the signaled pragmatic event-structure that Silverstein would call 'coincidence' (a label which corresponds directly with a term used by early $20^{\text {th }}$-century German specialists in Slavic linguistics for exactly this type of construction: Koinzidenzfall). The relation to problems of cognitive processibility is clear from a close study of the constraints on performativity of this kind: Only speech act verbs which do not require separate reference to properties of the describing act involved in the use of an explicitly metapragmatic verb (i.e. properties of the metapragmatic signaling event) for an adequate description of their meanings, and can be fully accounted for in terms of properties of the described act (i.e. of the signaled pragmatic event-structure) lend themselves to performative use; if this condition is not satisfied, a conceptual distance is involved which blocks complete selfreferentiality (see Verschueren 1995c).

\subsection{Reflexive conceptualization}

A second type of functioning relates primarily to forms of explicit metalanguage, though its effects are often far from salient or only with difficulty accessible to consciousness. As already suggested, linguistic behavior - as a form of social behavior - cannot be understood without an understanding of the notions in terms of which the behavior is conceptualized by those engaged in it, whether as utterer or interpreter, i.e. without an understanding of the reflexive conceptualization that accompanies production and interpretation choices. (In terms of Figure 1, the metapragmatic functioning in question bears on degrees of salience of the very processes that form the DYNAMICS of meaning generation in language use.) Let us illustrate this with reference to (2), distributed by the United States Information Service on 11 February 1999 (numbers in square brackets added for easy reference; boldface, italics, and underligning added).

\section{b. [1] TEXT: ALBRIGHT THANKS MONTENEGRIN LEADER FOR SUPPORT ON KOSOVO}

[2] (SecState calls President Djukanovic Feb. 9)

[3] Washington - Secretary of State Madeleine Albright expressed U.S. thanks to the president of Montenegro for supporting international efforts to resolve the crisis in Kosovo. 
[4] In a call to President Miklo Djukanovic February 9, Albright assured him that "Montenegro's concerns would be kept in mind at the Kosovo settlement talks in Rambouillet, France," according to State Department spokesman James Rubin.

[5] Following is the text of the statement:

\section{[6] (Begin text)}

[7] U.S. Department of State

[8] Office of the Spokesman

[9] Press statement by James P. Rubin, Spokesman

[10] February 9, 1999

\section{[11] Secretary's Call to Montenegrin President Djukanovic}

[12] On February 9 Secretary Albright called Montenegrin President Djukanovic to thank him for his government's continued support for international efforts to resolve the Kosovo crisis. [13] The Secretary noted the constructive role Montenegro had played throughout the crisis and praised Montenegro for leading the way on democratization and economic reform in the Federal Republic of Yugoslavia (FRY).

[14] The Secretary took this opportunity to assure President Djukanovic that Montenegro's concerns would be kept in mind at the Kosovo settlement talks in Rambouillet, France. [15] In his February 5 letter to the secretary, President Djukanovic had stressed his government's support for any political settlement reached by the two parties that did not affect Montenegro's constitutional position in the FRY.

[16] Finally, the Secretary assured President Djukanovic that world attention on the Kosovo situation does not mean FRY President Milosevic has a free hand to cause problems elsewhere in the FRY or the region.

\section{[17] (End text)}

[18] NNNN

Looking at the stretches of explicit metalanguage, we find illustrations for the above claim on two levels, the level of reporting on verbal behavior as well as the self-referential level. First, with the exception of "calls" in [2], "a call" in [4], "Call" in [11], "called" in [12], and "letter" in [15] - which focus on a channel of communication - all italicized portions of text show that reporting on verbal behavior is inevitably interpretive. Within the context of this article it is not even possible to begin spelling out all implications of social and institutional meaning carried along by "expressed thanks" in [3], "assured" in [4] or even 
"statement" in [5]. All of these descriptive metapragmatic choices reflect assessments of the communicative status and meaning of the described speech events. The quality of the descriptions, then, depends crucially on the degree to which the reflected assessments match frames of meaning that inform the described events. In contexts of communicative controversy, therefore, the incidence of opposing interpretations, emerging from the descriptive choices, is extremely high. And as with all linguistic choice-making, even without the surfacing of oppositions any choice that is made carries along its contrast sets implicitly.

Second, on the self-referential level, boldface portions of text demonstrate clearly the importance that is generally attached to the interpretive status accorded to any speech event and the efforts that are often made to protect such status against contaminating reframings. It is the function of "TEXT" in [1], "Following is the text ..." in [5], "Begin text" in [6], and "End text" in [17] to define the status of the communication as precisely as possible in order to avoid the imposition of unintended frames of meaning. The same can be said of "Press statement" in [9], even though the speech event covered by this term is technically one layer removed from the superordinate structure of (2); I say 'technically' because the source of the two layers is the same. Communicative status protection is further accomplished by means of explicit source indications (underligned in [3], [4], [7], [8], and [9]).

Furthermore, there is a cyclic presence of these two levels (indicated here in bold italic). Thus "does not mean" in [16] is an attempt to freeze the interpretability of a communicative complex descriptively captured as "world attention". In this case, the form of autoreferentiality that is involved hinges on the fact that the U.S. is one of the main engineers of this "world attention" in spite of the descriptive distancing. (For an interesting study of how all the above metapragmatically shapes the communicative status of specific genres such as press releases, see Jacobs 1999.)

\section{Social implications of the functioning of metapragmatic awareness}

\subsection{Metapragmatic awareness and language ideologies}

Language use, just like other forms of social behavior, is interpreted by the actors involved. In the realm of social life in general, more or less coherent patterns of meaning which are felt to be so commonsensical that they are no longer questioned, thus feeding into taken-forgranted interpretations of activities and events, are usually called ideologies. ${ }^{9}$ Similarly, when elements of metapragmatic awareness can be seen to form persistent frames of interpretation related to the nature and social functioning of language which are no longer subject to doubt or questioning, it becomes possible to talk about ideologies of language. ${ }^{10}$

\footnotetext{
${ }^{9}$ For remarks on the pragmatics of ideology research, see Verschueren (1995a) and (1996); for an extensive exercise, see Blommaert \& Verschueren (1998).

${ }^{10}$ For an overview of research on language ideology, see Woolard \& Schieffelin (1994); for some recent contributions to this topic area, see Schieffelin et al. (eds.) (1998) and Blommaert (ed.) (1999).
} 
The latter become relevant topics of investigation in a variety of ways.

First of all, indeed, there is the inseparability of (local) linguistic practice and (systemic) metalinguistic conceptualization whenever language is used. As could already be concluded from example (2), much of the meaning negotiation that forms the dynamics of linguistic interaction is a struggle over the communicative status of utterances, involving norms (generally accepted or hegemonically imposed even if not generally adhered to) against which the ongoing (or past, or future) behavior can be evaluated. Though this is most clearly the case in institutional settings (witness the acceptability rating of different types of questions and answers during a trial), it is an integral part of what goes on in everyday conversations as well (at any level of choice-making, even at the level of language choice in a multilingual context - see e.g. Meeuwis 1997), so that understanding these processes is necessary for any adequate pragmatic analysis.

Second, under certain circumstances the 'struggle' may be suspended in favor of facile judgment. This is most typically the case when interpretations informed by habitual conceptualizations are not subject to further negotiation. This may be a purely personal or occasion-specific occurrence. But it may also result from the incompatibility of aspects of communicative style (a notion which would not make sense without the metapragmatic level) as documented in the literature on intercultural communication (e.g. Gumperz 1982) or on international news reporting (e.g. Verschueren 1985b, 1989a). What happens in such cases is that the experience of the naturalness of the invoked normativity, resulting directly from interpretation and conceptualization habits rooted in or related to ideologies of language, interferes with further meaning negotiation (a process which may be greatly enhanced by the absence of any direct interaction). Insight into the ingredients of language ideologies may therefore help us to understand what goes on in such specific settings.

By way of illustration, in order to show that none of this is innocent, take example (3), which is an extract from an official report following interviews with an asylum seeker as part of the procedure to determine eligibility for refugee status in Belgium. (The example is borrowed from Blommaert 1999.)

(3) It has to be noted that the concerned remains very vague at certain points. Thus he is unable to provide details about the precise content of his job as 'political informant'. Furthermore, the account of his escape lacks credibility. Thus it is unlikely that the concerned could steal military clothes and weapons without being noticed and that he could consequently climb over the prison wall.

It is also unlikely that the concerned and his wife could pass the passport control at Zaventem bearing a passport lacking their names and their pictures.

Furthermore, the itinerary of the concerned is impossible to verify due to a lack of travel documents.

The statements of the concerned contain contradictions when compared to his wife's account. Thus he declares that the passports which they received from the priest were already completely in order at the time they left Angola. His wife claims that they still had to apply for visa in Zaïre.

The phrases in italics are clearly not value-free descriptions. They focus on (I) 
commonsense plausibility and hence the trustworthiness of the applicants, (ii) the need for documentary evidence, and (iii) the nature of the communicative activities that make up the summarized narrative. The interpretations are characterized by automatic applications of specific types of normativity, the validity of which is not questioned. As to (i), the inability to produce a convincing story is seen as a sign of lying - a judgment that is probably extended beyond the 'doubtful' stretches to the very grounds for seeking asylum. As to (ii), the norms of administrative records are imposed on the telling of part of a life story. As to (iii), a notion such as contradiction is applied across different narratives as if such an application would not require the careful comparison of entire discourse contexts.

Third, the workings of language ideologies can not only be observed in forms of everyday interaction, institutional discourse, education, political rhetoric, mass communication, and the like, but also linguistic theories and analyses themselves do not escape from their influence. Silverstein (1979) may have been the first to point this out convincingly. Others, mostly linguistic anthropologists, followed suit in their criticisms of the Gricean and Searlean paradigms in pragmatics, confronting what linguists took for granted with observable, situated linguistic practice. That the history of linguistics itself (or pragmatics in particular) is not free from 'ideological' fluctuations is easy to observe; just think of the notion of linguistic relativity, proposed as a principle by Whorf, elevated to the level of dogma by his followers, turned into a dirty word among linguists in the sixties and seventies, and resurrected during the last ten to fifteen years (witness Gumperz \& Levinson (eds) 1996). From such observations we should learn that a constant monitoring of linguistic rhetoric in view of the ideological underpinnings of theories and analyses is not a luxury but a prerequisite for the advancement of linguistic pragmatics. (For an excellent example of such a critical approach to some of the linguistic literature, see Eelen's (1999) study of politeness research.)

\subsection{Metapragmatic awareness and identity construction}

Example (2) illustrates (in the underligned segments) how explicit attempts may be made to define the identity of the utterer or of the source of a message. The functioning of aspects of 'identity' would be hard to understand without reference to metapragmatiuc awareness. Most of the time it does not take the explicit form exemplified in (2), but it hinges on the subtle signaling involved in category-specific linguistic choices. Typical examples are forms of code switching (Gumperz 1982; Auer 1998) which become symbolic for specific social groups or formations of which membership is typically required for an utterer to be able to use a certain code; similarly, switching to a code one assumes the interpreter to be more familiar with accomplishes a process of other-categorization (see e.g. Hinnenkamp 1991). In conversation analysis, the entire literature on participation frameworks and membership categorization devices (see e.g. Antaki \& Widdicombe (eds.) 1998) is fundamentally concerned with the metapragmatics of identity construction. That identities are not 'given' but dynamically constructed in discourse - which further strengthens the assumption that metapragmatic awareness must be fundamentally involved - should be clear from a small example such as (4). This example (borrowed from D'hondt 2000) is a fragment from an ordinary conversation in the streets of Dar es Salaam (from which I have eliminated the original Kiswahili and the transcription conventions). 
(4) [N \& G talking about a soccer game they want to watch]

$\mathrm{N}$ : If it is granted to us.

G: Inshallah, inshallah, inshallah.

$\mathrm{N}$ : Eh? But in the mosque I do not see you?

G: That's where I am going right now.

As D'hondt points out, reference to a future course of events (the watching of a soccer game) - which should not simply be taken for granted by humans who cannot themselves control the future - is followed by the formulaic "If it is granted to us," which is then acknowledged and upgraded by G's series of "Inshallah's" ('If God wishes'). Though there is a categorial relationship between G's utterance and being a muslim, the value of G's linguistic choices as identity markers is variable. The signaling of identity could have been left entirely implicit, and its contextual relevance might have been nil. But then $\mathrm{N}$ taps into his metapragmatic awareness of the identity-signaling value or potential of the linguistic choices made by $\mathrm{G}$ to topicalize it explicitly in "But in the mosque I do not see you?", a topicalization which is accepted by $\mathrm{G}$ in his next response.

\section{Conclusion}

There is a reason why the title of this article is simply "Notes on ...". The task of completing the picture is far beyond its scope. By way of conclusion, I would simply like to draw the attention once more to the fact that metapragmatic awareness - and hence all of its linguistic manifestations - contributes crucially to the generation and negotiation of meaning which, in a pragmatic theory, is the core process of what language use is all about. This is not only the case at the obvious levels of conscious self-monitoring and audience design, but also at much lower levels of salience where it underlies and contributes to the meaning of most aspects of linguistic choice-making. Singling the metalinguistic dimension of language out for separate scientific attention is therefore a valuable heuristic strategy in order not to forget its fundamental contribution to all pragmatic functioning.

\section{References}

Antaki, Charles, and Sue Widdicombe (eds.) (1998) Identities in Talk. London: Sage.

Auer, Peter (1998) Code-switching in Conversation. London: Routledge.

Blommaert, Jan (1999) Investigating narrative inequality: 'Home narratives' of African asylum seekers in Belgium. Working Papers on Language, Power \& Identity 1 (http://bank.rug.ac.be/lpi/)

Blommaert, Jan (ed.) (1999) Language Ideological Debates. Berlin: Mouton de Gruyter.

Blommaert, Jan, and Jef Verschueren (1998) Debating Diversity: Analysing the Discourse of Tolerance. London: Routledge.

Caffi, Claudia (1998) Metapragmatics. In Jacob L. Mey (ed.), Concise Encyclopedia of Pragmatics. 
Amsterdam: Elsevier, pp. 581-586.

Caffi, Claudia (ed.) (1984) Metapragmatics. Special issue of Journal of Pragmatics 8.4: 433-592.

Carnap, Rudolph (1937) Logical Syntax of Language. New York.

D'hondt, Sigurd (1999) Conversaation Analysis and History: Practical and Discursive Understanding in Quarrels among Dar es Salaam Adolescents. Univ. of Antwerp Ph.D. dissertation.

Eelen, Gino (1999) Ideology in Politeness: A Critical Analysis. Univ. of Antwerp Ph.D. dissertation.

Errington, Joseph J. (1988) Structure and Style in Javanese. Philadelphia: University of Pennsylvania Press.

Gumperz, John J. (1982) Discourse Strategies. Cambridge: Cambridge University Press.

Gumperz, John J., and Stephen C. Levinson (eds.) (1996) Rethinking Linguistic Relativity. Cambridge: Cambridge University Press.

Hickmann, Maya (1993) The boundaries of reported speech in narrative discourse: Some developmental aspects. In J. Lucy (ed.) (1993), pp. 63-90.

Hinnenkamp, Volker (1991) Talking a person into interethnic distinction. In J. Blommaert \& J. Verschueren (eds.), The Pragmatics of intercultural and International Communication. Amsterdam/ Philadelphia: John Benjamins, pp. 91-110.

Hoenigswald, H. (1966) A proposal for the study of folk-linguistics. In W. Bright (ed.), Sociolinguistics. The Hague: Mouton, pp. 16-26.

Jacobs, Geert (1999) Preformulating the News: An Analysis of the Metapragmatics of Press Releases. Amsterdam/Philadelphia: John Benjamins Publishing Company.

Jakobson, Roman (1960) Linguistics and poetics. In Thomas A. Sebeok (ed.), Style in language. Cambridge, Mass.: MIT Press, pp. 350-377.

Jakobson, Roman (1971) [1957] Shifters, verbal categories, and the Russian verb. In Selected writings II. The Hague: Mouton, pp. 130-147.

Jakobson, Roman (1985) [1956] Metalanguage as a linguistic problem. In Selected writings VII. Berlin: Mouton De Gruyter, pp. 113-121.

Jespersen, Otto (1921) Language. New York.

Kiefer, Ferenc, and Jef Verschueren (eds.) (1988) Metapragmatic Terms. Special issue of Acta Linguistica Hungaricae 38.1-289.

Lucy, John A. (ed.) (1993) Reflexive Language. Cambridge: Cambridge University Press.

Meeuwis, Michael (1997) Constructing Sociolinguistic Consensus: A Linguistic Ethnography of the Zairian Community in Antwerp, Belgium. Univ. of Antwerp Ph.D. dissertation.

Mey, Jacob (1993) Pragmatics. Oxford: Basil Blackwell.

Östman, Jan-Ola (1986) Pragmatics as Implicitness. UMI no. 8624885.

Preston, Dennis (2000) A renewed proposal for the study off folk linguistics. In Joy Kreeft Peyton, Peg 
Griffen, Walt Wolfram, and Ralph Fasold (eds.), Language in Action. Cresskill, NJ: Hampton Press, pp. 113138.

Schieffelin, Bambi, Kathryn Woolard, and Paul Kroskrity (eds.) (1998) Language Ideologies. Oxford: Oxford University Press.

Silverstein, Michael (1976) Shifters, linguistic categories, and cultural description. In K. Basso \& H. Selby (eds.,) Meaning in anthropology. Albuquerque: Univ. of New Mexico Press, pp. 11-55.

Silverstein, Michael (1979) Language structure and linguistic ideology. In P.R. Clyne, W.F. Hanks \& C.L. Hofbauer (eds), The Elements: A Parasession on Linguistic Units and Levels. Chicago: Chicago Linguistic Society, pp. 193-247.

Silverstein, Michael (1981) The limits of awareness. Sociolinguistic Working Paper 84.

Silverstein, Michael (1993) Metapragmatic discourse and metapragmatic function. In John A. Lucy (ed.), pp. $33-58$

Tomasello, Michael (1999) The Cultural Origins of Human Cognition. Cambridge, Mass.: Harvard University Press.

Verschueren, Jef (1985a) What people say they do with words: Prolegomena to an empirical-conceptual approach to linguistic action. Norwood, NJ: Ablex.

Verschueren, Jef (1985b) International News Reporting: Metapragmatic Metaphors and the U-2. Amsterdam / Philadelphia: John Benjamins Publishing Company.

Verschueren, Jef (1989a) English as object and medium of (mis)understanding. In Ofelia García \& Ricardo Otheguy (eds), English Across Cultures - Cultures Across English: A Reader in Cross-Cultural Communication. Berlin: Mouton de Gruyter, pp. 31-53.

Verschueren, Jef (1989b) Language on language: Toward metapragmatic universals. Papers in Pragmatics 3.2: 1-144.

Verschueren, Jef(1995a) The pragmatic return to meaning: Notes on the dynamics of communication, degrees of salience, and communicative transparency. Journal of Linguistic Anthropology 5: 127-156.

Verschueren, Jef (1995b) Metapragmatics. In J. Verschueren, J.-O. Östman \& J. Blommaert (eds.), Handbook of Pragmatics: Manual. Amsterdam/Philadelphia: John Benjamins Publishing Company, pp. 367-371.

Verschueren, Jef (1995c) The conceptual basis of performativity. In M. Shibatani \& S. Thompson (eds.), Essays in Semantics and Pragmatics. Amsterdam/ Philadelphia: John Benjamins Publishing Company, pp. 299-321.

Verschueren, Jef (1996) Contrastive ideology research: Aspects of a pragmatic methodology. Language Sciences 18.3/4: 589-603.

Verschueren, Jef (1999) Understanding Pragmatics. London: Edward Arnold.

Verschueren, Jef (ed.) (1987) Linguistic action: Some empirical-conceptual studies. Norwood, NJ: Ablex.

Vološinov, V.N. (1930) Marksizm i filosofija jazyka [Marxism and the philosophy of language]. Leningrad.

Vygotsky, L.S. (1978) Mind in Society: The Development of Higher Psychological Processes. Cambridge, Mass.: Harvard University Press. 
Woolard, Kathryn A. \& Bambi B. Schieffelin (1994) "Language ideology.” Annual Review of Anthropology 23: 55-82. 